\title{
Pemantauan Kecemasan dan Lama Persalinan Kala I pada Ibu Bersalin dengan Pelaksanaan Yoga Kehamilan
}

\author{
Eva Santi Hutasoit ${ }^{1}$, Novi Yanti ${ }^{2}$, Susani Hayati ${ }^{3}$, Yessi Azwar ${ }^{4}$, Noviyanti ${ }^{5}$, Khoriah Utami $^{6}$ \\ Email: azwaryessi@gmail.com \\ ${ }^{1,4}$ Dosen Prodi D III Kebidanan Stikes Payung Negeri Pekanbaru \\ ${ }^{2}$ Dosen D III Keperawatan Stikes Payung Negeri Pekanbaru \\ ${ }^{3}$ Dosen S1 Kebidanan Stikes Payung Negeri Pekanbaru \\ ${ }^{5}$ Dosen Program Studi S1 Kesehatan dan Keselamatan Kerja Universitas Ibnu Sina \\ ${ }^{6}$ Mahasiswa Prodi D III Kebidanan Stikes Payung Negeri Pekanbaru
}

\begin{abstract}
Abstrak
Masa kehamilan membuat wanita banyak mengalami perubahan. Perubahan pada tubuh dan pikiran dapat menyebabkan ketidaknyaman pada ibu hamil. Selain ketidaknyamanan fisik yang dirasakan, ketidaknyamanan psikologis juga sering terjadi. Masalah dengan prevalensi yang sering terjadi diantaranya kecemasan dan depresi pada kehamilan. Salah satu intervensi yang dapat mengurangi kecemasan dapat dilakukan latihan fisik seperti yoga. Manfaat yang didapatkan dari yoga antara lain memberikan rasa nyaman, stress menurun, nyeri persalinan berkurang, self efficacy pada persalinan, kualitas hidup meningkat, hubungan interpersonal, fungsi sistem saraf otonom, dan durasi persalinan menjadi singkat. Tujuan pengabdian ini untuk untuk memperkenalkan kepada masyarakat manfaat yoga kehamilan terhadap pengurangan kecemasan ibu dalam mengahadapi persalinan dan mempercepat persalinan kala I pada ibu bersalin di kota Pekanbaru. Pengabdian masyarakat ini dilakukan selama 3 bulan. Program pengabdian ini mempunyai beberapa kegiatan yaitu : melaksanakan pemeriksaan kehamilan kepada ibu hamil, melaksanakan kegiatan senam yoga dalam kehamilan dan menilai hasil dari kegiatan senam yoga dalam kehamilan. Pengabdian ini dilakukan di wilayah kerja Puskesmas Payung Sekaki dengan jumlah ibu hamil yang dilatih senam yoga sebanyak 30 orang. Peserta pelatihan ini adalah ibu hamil yang kehamilannya berada pada trimester ke tiga. Luaran dari pengabdian masyarakat ini adalah terbentuknya komunitas senam yoga di wilayah Kerja Puskesmas Payung Sekaki. Dari hasil pelaksanaan senam yoga dalam kehamilan didapatkan bahwa senam yoga dalam kehamilan dapat mengurangi tingkat kecemasan ibu selama menghadapi persalinan. Dan dengan melaksanakan senam yoga maka lama kala 1 yang dihadapi oleh ibu selama bersalin $\leq 6 \mathrm{Jam}$.
\end{abstract}

Kata kunci: yoga; kehamilan; lama persalinan.

\begin{abstract}
Pregnancy makes women experience a lot of changes. Changes in the body and mind can cause discomfort in pregnant women. In addition to the physical discomfort felt, psychological discomfort is also common. Problems with common prevalence include anxiety and depression in pregnancy. One intervention that can reduce anxiety can be physical exercise such as yoga. The benefits obtained from yoga include providing a sense of comfort, decreasing stress, reducing labor pain, self-efficacy in childbirth, increasing quality of life, interpersonal relationships, autonomic nervous system function, and shortening the duration of labor. The purpose of this service is to introduce to the public the benefits of pregnancy yoga in reducing maternal anxiety in dealing with labor and accelerating the first stage of labor in women giving birth in Pekanbaru city. This community service was carried out for 3 months. This service program has several activities, namely: carrying out pregnancy checks for pregnant women, carrying out yoga exercise activities in pregnancy and assessing the results of yoga exercise activities in pregnancy. This service is carried out in the work area of the Payung Sekaki Health Center with a total of 30
\end{abstract}


pregnant women who are trained in yoga exercises. Participants in this training are pregnant women whose pregnancy is in the third trimester. The output of this community service is the formation of a yoga gymnastics community in the Working area of the Payung Sekaki Health Center. From the results of the implementation of yoga exercise in pregnancy, it was found that yoga exercise in pregnancy can reduce the level of maternal anxiety during childbirth. And by doing yoga exercises, the mother's 1st period of time during childbirth is 6 hours.

Keywords: yoga; pregnancy; length of labor.

\section{Pendahuluan}

Kehamilan adalah proses dan peristiwa yang sangat unik dan berbeda satu dengan yang lain. Wanita yang sedang berada dalam masa kehamilan banyak mengalami perubahan. Perubahan pada tubuh dan pikiran dapat menyebabkan ketidaknyaman pada ibu hamil. Selain ketidaknyamanan fisik yang dirasakan, ketidaknyamanan psikologis juga sering terjadi (Aprillia, 2019).

Kecemasan dan depresi pada kehamilan merupakan masalah dengan prevalensi yang cukup tinggi yaitu sekitar 12,5-42\%. Kejadian kecemasan dan depresi pada negara maju sekitar $7-20 \%$ dan di negara berkembang sekitar lebih dari 20\% (Zafariyana, 2018). Dalam mengatasi masalah tersebut diperlukan pendekatan yang berkualitas yang dimulai sejak perencanaan kehamilan dan selama masa kehamilan (Tiawaningrum, 2018) .Salah satu intervensi yang dapat dilakukan adalah latihan fisik seperti yoga (Pariante, 2016). Berlatih senam hamil yoga merupakan salah satu solusi yang menunjang proses kehamilan, kelahiran dan merupakan sarana untuk belajar kelompok tentang kesehatan ibu hamil, dalam bentuk tatap muka yang bertujuan meningkatkan pengetahuan dan keterampilan mengenai kehamilan, persalinan, perawatan nifas dan perawatan bayi baru lahir
(Wiramihardja, 2015).

Yoga adalah sejenis olah tubuh, pikiran dan mental yang membantu ibu hamil melenturkan persendian dan menenangkan pikiran terutama dalam trimester III. Yoga tidak hanya bermanfaat pada kebugaran fisik, tetapi juga mental karena latihan yoga mengajarkan cara bernafas dalam secara sadar dan rileks. Latihan ini akan membantu ibu hamil mengahadapi persalinan. Latihan yoga yang dikombinasikan dengan latihan kardiovaskular (seperti berjalan) dapat menjadi cara yang ideal bagi ibu hamil agar tetap bugar (Ayuningtyas,2019). Yoga dapat menurunkan stres, meningkatkan kualitas hidup, self efficacy pada persalinan, hubungan interpersonal, fungsi sistem saraf otonom, memberi rasa nyaman, mengurangi atau menurunkan nyeri persalinan dan memperpendek durasi persalinan (Katz, 2012).

Tujuan pengabdian ini adalah untuk memperkenalkan kepada masyarakat manfaat yoga kehamilan terhadap kecemasan dan lama persalinan kala I pada ibu bersalin di kota Pekanbaru. Luaran dari pengabdian masyarakat ini adalah terbentuknya komunitas senam yoga di wilayah Kerja Puskesmas Payung Sekaki. 


\section{Metode}

Program pelaksanaan senam yoga ibu hamil ini melalui beberapa tahap. Adapun tahap-tahap tersebut adalah :

a. Tahap Perizinan

Pada tahap ini perizinan pelaksanaan senam yoga dimintakan ke Puskesmas. Peserta yang terlibat dalam kegiatan ini adalah ibu hamil trimester tiga yang berada di wilayah kerja puskesmas sejumlah 30 orang.

b. Tahap Persiapan

1) Pada tahap ini mulai dilaksanakan anamnesa dan inform consent peserta yang akan mengikuti senam yoga dalam kehamilan.

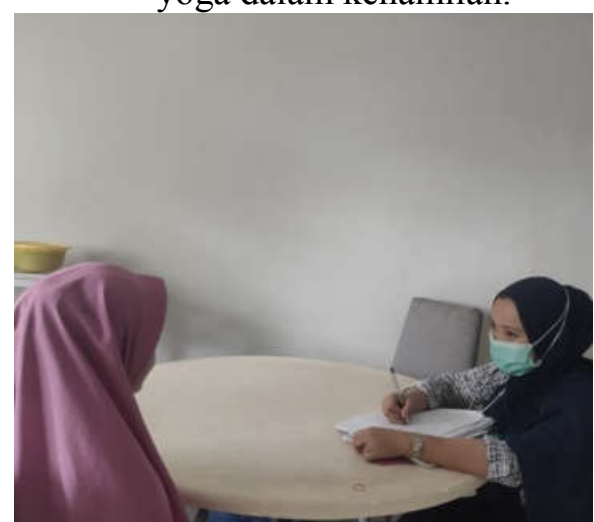

Gambar 2.1. Anamnesa Pasien dan inform consent
2) Persiapan yang kedua adalah persiapan ruangan untuk pelaksanaan senam yoga. Senam yoga dilaksanakan di ruangan komplementer Stikes Payung Negeri Pekanbaru

c. Tahap Pelaksanaan

Pelaksanaan senam yoga ibu hamil ini dilaksanakan setiap 1 minggu sekali. Sebelum melakasanakan senam yoga ibu hamil diberikan kuesioner untuk menilai tingkat kecemasan ibu sebelum menghadapi persalinan. Pada saat melaksanakan senam yoga dalam kehamilan ibu diberikan alunan musik yoga yang nyaman. Setelah dikakuan senam yoga maka ibu diberikan pemeriksaan kehamilan untuk menilai kondisi ibu dan janin.
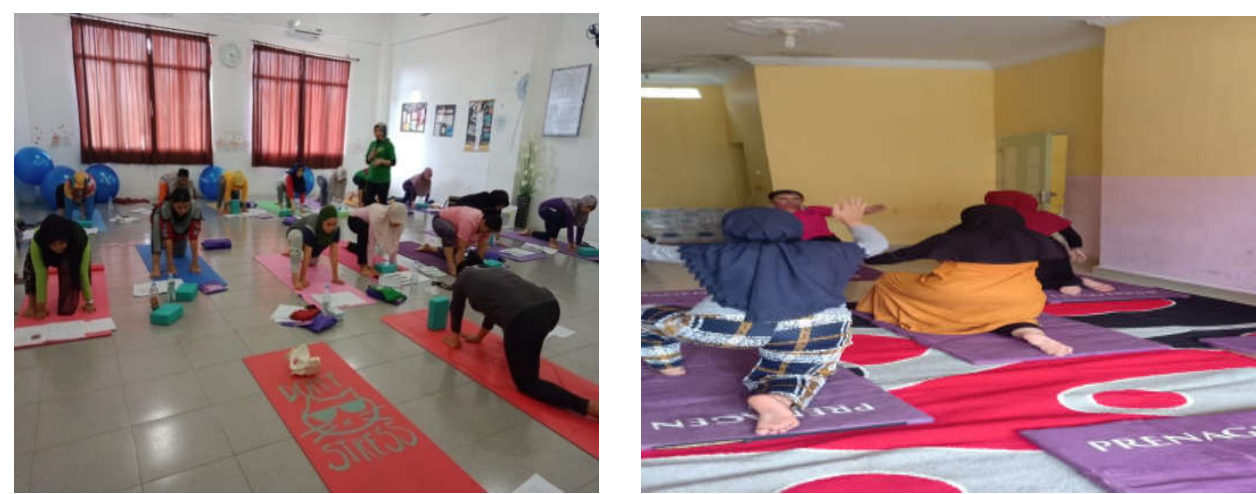

Gambar 2.2. Pelaksanaan Senam Yoga 


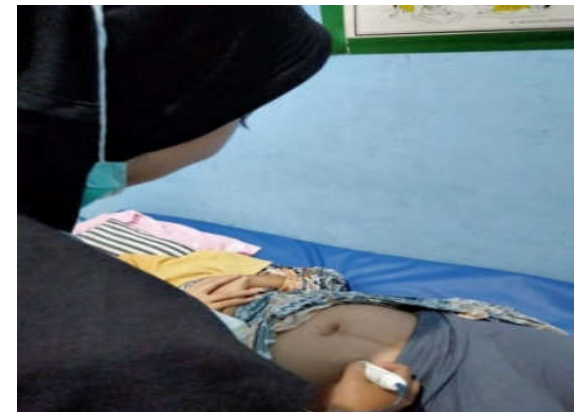

Gambar 2.3. Pemeriksaan Kehamilan d. Tahap Evaluasi

Tahap evaluasi dilaksanakan pada saat ibu akan menghadapi persalinan. Ibu akan dievaluasi tingkat kecemasannya dam lama pelaksanaan kala 1

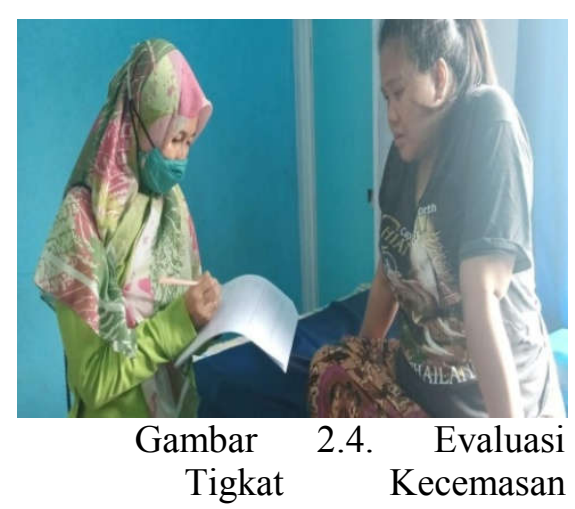

perizinan, persiapan, pelaksanaan dan evaluasi. Kegiatan senan yoga dalam kehamilan ini dilaksanakan setiap satu minggu sekali. Hasil dari kegiatan ini adalah :

Tabel 3. Hasil kegiatan

\begin{tabular}{ccccc}
\multirow{2}{*}{ Minggu Ke } & \multicolumn{2}{c}{ Tingkat kesemasan } & \multicolumn{2}{c}{ Lama kala 1 } \\
\cline { 2 - 5 } & Cemas & Tidak cemas & $\leq 6$ Jam & $>$ 6 Jam \\
\hline 1 & 17 & 13 & & \\
\hline 2 & 19 & 11 & & \\
\hline 3 & 19 & 11 & & \\
\hline 4 & 15 & 15 & & \\
\hline 5 & 12 & 18 & & \\
\hline 6 & 10 & 20 & & \\
\hline 7 & 10 & 20 & & \\
\hline 8 & 6 & 24 & & \\
\hline 9 & 0 & 30 & 15 & \\
\hline 10 & 0 & 10 & 25 & \\
\hline 11 & & & 27 & 2 \\
\hline 12 & & & 28 & 1
\end{tabular}

Dari hasil pelaksanaan senam yoga dalam kehamilan didapatkan bahwa senam yoga dalam kehamilan dapat mengurangi tingkat kecemasan ibu selama menghadapi persalinan. Dan dengan melaksanakan senam yoga maka lama kala 1 yang dihadapi oleh ibu selama bersalin $\leq 6 \mathrm{Jam}$. 
Hal wajar apabila setiap manusia pernah dialami kecemasan. Kecemasan merupakan suatu perasaan saat seseorang merasa ketakutan atau kehilangan kepercayaan diri yang tidak jelas asal maupun wujudnya yang sifatnya umum (Aprillia, 2019). Hampir setiap orang pada waktu tertentu dalam kehidupannya dapat merasakan kecemasan dan ini merupakan reaksi normal terhadap situasi yang sangat menekan kehidupan seseorang. Gejala kecemasan bisa muncul sendiri atau bergabung dengan gejala-gejala lain dari berbagai gangguan emosi (Pariante, 2016). Apabila ibu yang mengalami stress, akan terjadi pelepasan hormone stress akibat sinyal yang berjalan lewat Hipothalamic-Pituitary-Adrenal

(HPA) dan berakibat terjadi vasokonstriksi sistematik, dan juga terjadi kontriksi vaso utero plasenta yang berdampak pada aliran darah di dalam Rahim tergangu, sehingga berpengaruh pada penyampaian oksigen $(\mathrm{O} 2)$ kedalam miometrium. Kejadian tersebut menyebabkan makin lamaya proses persalinan (partus lama) sehingga janin dapat mengalami fetal distress. Stress akibat kecemasan menghadapi persalinan tidak hanya berakibat pada ibu dan juga berdampak padajanin (Ayuningtyas, 2019). Kecemasan selama kehamilan, maka dapat dikurangi dengan rutin melakukan senam Yoga (Katz, 2012).

Senam yang mengolah tubuh, pikiran dan mental yang dapat membantu ibu hamil melenturkan persendian dan menenangkan pikiran terutama dalam trimester III merupakan bagian dari senam yoga. Yoga tidak hanya bermanfaat pada kebugaran fisik, tetapi juga mental karena latihan yoga mengajarkan cara bernafas dalam secara sadar dan rileks. Latihan ini akan membantu ibu hamil menghadapi persalinan (Zafariana, 2018). Stres dapat diturunkan dengan rutin melakukan Yoga, yoga juga meningkatkan kualitas hidup, self efficacy pada persalinan, hubungan interpersonal, fungsi sistem saraf otonom, memberi rasa nyaman, mengurangi atau menurunkan nyeri persalinan dan memperpendek durasi persalinan (Tiawaningrum, 2018).

Servik akan mulai menipis dan membuka pada awal dimulainya proses persalinan dan akibat langsung dari kontraksi. Pada persalinan akan terjadi kontraksi uterus yang merupakan kontraksi otot fisiologis yang menimbulkan nyeri pada tubuh dan akan terjadi lebih sering, lebih lama, dan intensitasnya semakin kua (Atuningtyas, 2019).

\section{Kesimpulan}

Berdasarkan hasil pelaksanaan kegiatan senam yoga pada ibu hamil dapat disimpulkan yaitu Senam yoga dalam kehamilan dapat mengurangi tingkat kecemasan ibu dalam menghadapi persalinan sehingga memberikan rasa nyama pada ibu selama persalinan, Serta Senam yoga dalam kehamilan dapat meningkatkan kualitas hidup, self efficacy pada persalinan, hubungan interpersonal, fungsi sistem saraf otonom, memberi rasa nyaman, mengurangi atau menurunkan nyeri persalinan dan memperpendek durasi persalinan 


\section{Daftar Pustaka}

[1] A. Biaggi, S. Conroy, S. Pawlby, and C. M. Pariente, "Identifying the women at risk of antenatal anxiety and depression: A systematic review," J. Affect. Disord, vol. 191, pp. 62-77, 2017.

[2] I. F. Ayuningtyas, Kebidanan Komplementer. Yogyakarta: Pustaka Baru Press, 2019.

[3] I. Mulyati and W. Zafariyana, "Pengaruh Prenatal Yoga Terhadap Kecemasan Dalam Menghadapi Persalinan Pada Primigravida Trimester III Di Jamsin Mq Medika Kota Bandung Tahun 2018," Pros. Pertem. Ilm. Nas. Penelit. Pengabdi. Masy. (PINLITAMAS 1), vol. 1, no. 1, pp. 424-431, 2018.

[4] K. Curtis, A. Weinrib, and J. Katz, "Systematic review of yoga for pregnant women: Current status and future directions," Evidence-based Complement. Altern. Med, vol. 2012, 2012.

[5] N. Ridhani, S. Prastiwi, and T. Nurmaningsih, "Gambaran Tingkat Kecemasan Ibu Bersalin Yang Akan Menghadapi Sectio Caesarea Di Rumah Sakit Baptis," Nurs. News, vol. 2, no. 2, pp. 71-79, 2017.
[6] R. Savitri, Kecemasan. Jakarta: Pustaka Populer Obor, 2015.

[7] T. Eni, R. Devi, K. Sulastriningsih, and E. Tiawaningrum, "PENGARUH YOGA PRENATAL DAN HYPNOBIRTHING

TERHADAP

PROSES PERSALINAN KALA I PADA IBU BERSALIN DI BPM RESTU DEPOK PERIODE JANUARI-JUNI TAHUN 2017 THE INFLUENCE OF HYPNOBIRTHING AND YOGA ON LABOR PROCESS ON ONE ON MOTHER LABOR," vol. 5, no. 1, pp. 26-32, 2018.

[8] W. Sutarjo, Pengantar Psikologi Abnormal. Bandung: PT. Resika Aditama, 2015.

[9] Y. Aprilia, Bebas Takut Hamil dan Melahirkan. Jakarta: Gramedia Pustaka Utama, 2019. 